\title{
A FILOSOFIA DA HISTÓRIA DE DUHEM: NATUREZA E FUNÇÃO'
}

\author{
José Raymundo Novaes Chiappin \\ Departamento de Economia-Departamento de Filosofia/USP
}

Carolina Leister

Escola de Economia de São Paulo/FGV

\section{Resumo}

Este artigo é construído no intuito de cumprir dois objetivos: o primeiro deles é discutir a natureza da filosofia da história de Duhem como empirista, anticonvencionalista e, principalmente, continuísta; o segundo é mostrar que uma das funções dessa filosofia da história é a de justificar princípios epistemológicos, como o princípio que afirma que a concepção da ciência é um tertius entre dogmatismo e ceticismo. Segue-se, desses dois objetivos, a naturalização da epistemologia em Duhem.

\section{Pallavras-chave}

filosofia da história $\bullet$ princípio da continuidade $\bullet$ justificação.

\section{Abstract}

This article has two objectives: the first is to discuss the nature of Duhem's philosophy of history as empiric, anti-conventionalist, and mainly continuist; the second is to show that one of its functions is to justify epistemological principles such as the one which establishes that the conception of science is a tertium quid between dogmatism and skepticism. Follows from these two objectives, the naturalization of epistemology in Duhem.

\section{Keywords}

philosophy of history $\bullet$ continuity principle $\bullet$ justification.

\footnotetext{
${ }^{1}$ Gostaríamos de agradecer aos dois pareceristas anônimos da Revista de História pela leitura atenta deste artigo e por terem chamado a atenção sobre alguns pontos dessa argumentação de modo a tornar a redação deste texto mais clara e precisa.
} 


\section{A natureza da filosofia da história}

Neste artigo pretendemos discutir a filosofia da história de Duhem, descrevendo sua natureza e sua função, sustentando ser ela um dos componentes importantes de sua concepção metodológica da ciência, tendo sido elaborada como uma concepção que se pretende continuísta, empirista e anticonvencionalista. Admitindo que não há área do conhecimento que possa dispensar o papel da história, a ciência transformou a história da ciência em estudo obrigatório para avaliar corretamente a contribuição do passado para seus avanços modernos. A filosofia fez da história da filosofia seu verdadeiro laboratório, semelhante àquele que é a própria natureza, ou ainda àqueles construídos artificialmente pelos cientistas da natureza. Para certas áreas, o papel da história é absolutamente indispensável e, às vezes, chega a se confundir com a própria atividade, como é o caso da filosofia. Um estudo de Platão, Descartes, Hobbes, Locke, Hume, Kant e Hegel equivale ao estudo de modelos particulares elaborados pelos físicos, como o modelo do plano inclinado na mecânica de Galileu, o modelo do prisma e da gota d'água para Descartes e o modelo do prisma para Newton no estudo do arco-íris e da teoria das cores, o modelo de Ising e de Heisenberg para os físicos estatísticos, o modelo do dilema dos prisioneiros em jogos, política, filosofia e economia. Assim como os cientistas usam modelos para conhecer a natureza e aprofundar seu conhecimento da mesma, os filósofos estudam os filósofos pertencentes à história da filosofia como modelos de filosofar e de conhecimento filosófico sobre os temas de reflexão.

Nesse contexto, o tema e o problema do fundamento epistemológico e metodológico da história requerem reflexão indispensável sobre o que significa fazer e analisar a história. Esse é o tema que se convencionou chamar de filosofia da história e que deve servir de preâmbulo para o adequado enquadramento teórico do assunto deste artigo. A filosofia francesa das décadas de 1950 e 1960 teve como um de seus principais tópicos de interesse o da filosofia da história. Duas figuras centrais sobre esse assunto são Alexandre Koyré e Gaston Bachelard, autores que fazem a conexão entre duas gerações completamente antagônicas de pensadores que conduziram uma profunda reflexão sobre a história e que fizeram dela um componente essencial de suas teorias e investigações. A primeira geração é aquela de Pierre Duhem e Emile Meyerson que corresponde ao final do século XIX e começo do século XX. A outra, que pode ser denominada de terceira geração, é aquela de Canguilhem, Foucault e Althusser na França e Thomas Kuhn nos Estados Unidos que emergem depois da década de 50 do 
século XX como herdeiros da concepção da história de Koyré e Bachelard. Estes últimos, portanto, são identificados como a segunda geração. A primeira geração tem como o mais importante princípio epistemológico o princípio da continuidade do desenvolvimento da história, sua cumulatividade e seu caráter convergentista e teleológico, com Duhem, e o princípio da continuidade entre o senso comum e o conhecimento científico, com Emile Meyerson. ${ }^{2}$ Esses dois autores têm posições completamente antagônicas quanto à natureza da ciência. Duhem defende o princípio da interpretação teórica dos dados e, portanto, que há logicamente uma distinção entre o senso comum e o conhecimento científico teórico, mesmo aceitando a existência de uma relação entre o senso comum e as leis empíricas, cuja classificação a física teórica deve promover. Duhem faz a crítica da teoria da relatividade, afirmando que essa teoria colide com o senso comum, ${ }^{3}$ que ela é uma aberração e que é fruto da mente alemã (geométrica) não-temperada com o senso comum. ${ }^{4}$ Uma razão possível, a ser discutida em outro lugar, seria que a teoria da relatividade não serviria para classificar as leis empíricas que mantêm relação com o senso comum?

Duhem defendeu a continuidade no desenvolvimento histórico, e em particular entre a ciência medieval e a moderna, como aplicação de seu princípio da continuidade à história, ${ }^{5}$ apontando como Galileu é herdeiro dos desenvolvimentos da ciência medieval. Alguns historiadores afirmam que, por essa razão, é um dos teóricos que mais contribuíram para destruir a ideia da Idade Média como Idade das Trevas. Emile Meyerson defende o princípio da continuidade entre o senso comum e o conhecimento científico e recebe a teoria da relatividade de Einstein como evidência favorável dessa continuidade pela sua ampliação e reforço. Duhem e Meyerson tiveram, pela grande produção de trabalhos em filosofia e história da ciência, uma influência extremamente forte em Koyré, que os menciona sistematicamente, e em Bachelard. No entanto, as concepções desses dois teóricos sobre a filosofia da história desenvolvem-se como radicalmente antagônicas àquelas de Meyerson e Duhem, em particular pela abordagem estruturalista da história que os conduz a uma concepção oposta à concepção da continuidade do progresso científico, da convergência

\footnotetext{
${ }^{2}$ MEYERSON, Emile. Identity and reality. New York: The Macmillan Co., 1930.

${ }^{3}$ DUHEM, Pierre. La science allemande. Paris: A. Hermann et fils, 1915, p. 271-272.

${ }^{4}$ Ibidem.

${ }^{5}$ CHIAPPIN, José Raymundo Novaes. Duhem's theory of science: an interplay between philosophy and history of science. Ph.D. thesis. Pittsburgh: University of Pittsburgh, 1989.
} 
e também da continuidade entre o senso comum e os conceitos científicos. As concepções sobre a ciência e a filosofia da história de Koyré e Bachelard são frutos das revoluções conceituais provocadas pela relatividade de Einstein e pela mecânica ondulatória de De Broglie.

Tanto Alexandre Koyré quanto Gaston Bachelard desenvolvem suas concepções, entre as décadas de 1930 e 1960, em oposição crítica aos pressupostos epistemológicos da história de Duhem e Meyerson, assim como às suas concepções de conhecimento, particularmente à sua aplicação do princípio da continuidade na história bem como na relação entre o senso comum e a ciência. A segunda geração substituiu o princípio da continuidade pelo princípio da ruptura, da descontinuidade e da mudança epistemológica no desenvolvimento histórico como na relação entre o senso comum e a ciência. Para Koyré, ${ }^{6}$ o principal exemplo da aplicação do princípio da mutação intelectual, como princípio da história não continuísta e estrutural, é aquele da ruptura epistemológica entre o mundo (finito) aristotélico e o mundo (infinito) de Galileu. Não há transição continuísta possível entre um e o outro. A geometrização do espaço e a destruição do cosmo aristotélico ${ }^{7}$ são dois pressupostos fundamentais dessa transição epistêmica. Não há como compará-los, pois cada um deles está encerrado em estruturas independentes articuladas por conceitos, princípios e regras que não se comunicam. A análise dessa transição por Koyré é um exemplo de sua abordagem epistemológica e metodológica do uso da descontinuidade em ambos os aspectos, histórico e da natureza de conhecimento, que propõem o senso comum e a ciência. Para Koyré, a passagem entre esses dois mundos é o resultado de um processo prolongado que produziu uma "verdadeira mutação intelectual", expressão que toma emprestada de Bachelard. ${ }^{8}$ Revoluções, para Koyré, são um longo processo de mutação intelectual. Segundo Koyré, ${ }^{9}$ não há a menor possibilidade de se elaborar uma lei como a da inércia no contexto da estrutura conceitual do cosmo aristotélico, uma vez que o conteúdo dessa lei pressupõe as propriedades de um universo infinito e da geometrização do espaço como aquela da isotropia do espaço.

\footnotetext{
${ }^{6}$ KOYRÉ, Alexandre. Études galiléennes. Paris: Hermann, 1966.

${ }^{7}$ Ibidem, p. 11-79.

${ }^{8}$ Ibidem, p. 11.

${ }^{9}$ Ibidem.
} 
Enquanto Alexandre Koyré foca a história da revolução da cinemática de Galileu $^{10}$ e, também, a história da revolução astronômica de Copérnico, Kepler e Borelli, ${ }^{11}$ Bachelard, por sua vez, tem por foco a história da transição da mecânica clássica de Newton para a mecânica relativista de Einstein. ${ }^{12}$ Sua preocupação quanto à história da física é a da transformação do mundo de Galileu e Descartes para aquele da mecânica relativista de Einstein e da microfísica da mecânica ondulatória de De Broglie. Segundo Bachelard, essa é uma revolução ainda mais profunda e significativa do que aquela da Idade Média para a Idade Moderna com Copérnico, Galileu, Descartes e Newton. Foi essa mudança, ou mutação intelectual, que destruiu toda a relação possível entre o mundo empírico, da observação, do senso comum, com o mundo da ciência. Não há mais continuidade possível entre a observação e a experimentação. Uma concepção da história com o pressuposto do princípio da continuidade e sua metodologia de operacionalização falhará em capturar as principais características dessa transição.

Além de compartilhar de alguns princípios bastante semelhantes àqueles de Koyré, que são a ruptura epistemológica e a descontinuidade entre o senso comum e a ciência, Bachelard procura também elaborar a natureza epistemológica das novas teorias científicas emergentes, tendo a teoria de Einstein como modelo. Com esses recursos, pretende substituir a epistemologia cartesiana por uma nova epistemologia capaz de capturar a natureza mais complexa da ciência trazida pela teoria da relatividade. Se a ciência, para Descartes e Galileu, pode aproximar-se sistematicamente do mundo empírico, tendo, por isso, um caráter empirista, o mesmo não pode mais ocorrer com a ciência de Einstein e de De Broglie. Na concepção epistemológica de Bachelard, a ciência que emerge do trabalho desses dois cientistas, seja com a relatividade, seja com a microfísica, rompe epistemologicamente com o senso comum e o mundo empírico. Ela passa a construir seus próprios objetos e seu próprio universo.

A transição da mecânica para a mecânica relativista é a transição do mundo da observação para o mundo construído pela razão. O mundo da ciência é o mundo do racionalismo, que é aquele dos objetos construídos pela razão. O mundo do racionalismo é o mundo da representação, o que significa a construção dos objetos e da relação entre eles. Essa concepção pode mesmo ser buscada

\footnotetext{
${ }^{10}$ Ibidem.

${ }^{11}$ KOYRÉ, Alexandre. La révolution astronomique. Paris: Hermann, 1974, p. 15-17.

${ }^{12}$ BACHELARD, Gaston. A filosofia do não. São Paulo: Abril Cultural, 1978.
} 
já com Descartes, quando este afirma que o objeto imediato do conhecimento é a ideia e não a coisa. No entanto, no racionalismo clássico, a representação precisa ser, seguindo o modelo geométrico, simples, clara e distinta. Não é isso o que acontece no racionalismo neoclássico que é o mundo de Einstein e de De Broglie: as representações são complexas, como a de partículas e ondas. Essa transição do clássico para o neoclássico é feita contra a resistência da antiga estrutura epistemológica que opõe a ela uma série de obstáculos epistemológicos que Bachelard denomina erros. A história da ciência é a história do esforço para superar os obstáculos epistemológicos com a retificação dos erros e a construção de um novo sistema estruturado de ligações cada vez mais racionais, com menos erros, e aplicado ao mundo real como teste de sua racionalidade. ${ }^{13}$ Trata-se agora de um racionalismo aplicado, portanto, diverso do idealismo, ainda que também construa seus próprios objetos. Igualmente, não se trata mais de uma epistemologia cartesiana, pois seus objetos e princípios são complexos. Esse é o tema de seus livros O novo espírito científico, ${ }^{14}$ A filosofia do não, ${ }^{15} \mathrm{~A}$ formação do espírito científico ${ }^{16}$ e $O$ compromisso racionalista,${ }^{17}$ ou seja, uma epistemologia não cartesiana. Assim, tanto a epistemologia quanto a concepção da história sofrem o impacto das novas teorias científicas. Os aspectos revolucionário, estrutural e complexo da ciência contemporânea levam à emergência de concepções da história mais apropriadas a essas novas características e atributos da ciência. A história adquire, assim, características estruturalistas e propriedades que contemplam a descontinuidade, mutações, rupturas e crises. Além disso, recentes ciências humanas empíricas, contemporâneas àquelas da relatividade e da microfísica, exigem como método uma nova maneira de fazer história, e isso é o que se dá com a antropologia de Lévi-Strauss que requer, para a narrativa consistente de seus dados e elementos, uma história de natureza estrutural. A antropologia como ciência empírica não pretende se reduzir a uma massa de dados e de categorias de classificação, ela requer uma narrativa, um roteiro, uma história que integra, articula e organiza os dados e suas relações em uma estrutura que lhes atribui significados. Não se trata mais de uma estrutura mitológica, mas de uma estrutura cuja narrativa tem suporte nas evidências

\footnotetext{
${ }^{13}$ Ibidem.

${ }^{14}$ Ibidem.

${ }^{15}$ Ibidem.

${ }^{16}$ BACHELARD, Gaston. A formação do espírito científico. Rio de Janeiro: Contraponto, 1999.

${ }^{17}$ BACHELARD, Gaston, op. cit., 1978.
} 
empíricas. Um elemento essencial da estrutura é a propriedade do fechamento e da autossuficiência e, portanto, da desconexão com outras narrativas. Neste contexto é que se dá o debate com Sartre sobre a filosofia da história. LéviStrauss rejeita o que ele entende como uma atribuição mitológica da história, i. e., uma concepção que toma a história como não científica. Ele a tem como uma narrativa estrutural de natureza empírica. Sua concepção estruturalista faz dele, também, um integrante legítimo dessa segunda geração de historiadores..$^{18}$ Não se pode descartar uma relação entre a noção de estrutura utilizada por esses autores e a ideia de Duhem, contra Descartes, de que o teste científico é sempre relativo a uma estrutura teórica e nunca a uma única proposição.

A terceira geração, formada por Canguilhem, Althusser, Foucault e Kuhn, incorpora também o pressuposto da descontinuidade como princípio e recurso metodológico da história que se articula em torno das ideias de ruptura, mutação intelectual, corte, salto, revolução, recorrência, estrutura, episteme e crise, assim como o pressuposto da descontinuidade entre o senso comum e a ciência. Assim como há, inerente à natureza do conhecimento científico como interpretação da natureza, a ideia de descontinuidade entre o senso comum e o conhecimento científico, devido à descontinuidade entre dados empíricos e dados científicos, há também, correlacionada a essa ideia, aquela da descontinuidade na história das ideias e dos conceitos científicos. Os autores da terceira geração têm como pressuposto epistemológico acerca da concepção da ciência o de que não há dados, mas apenas dados interpretados teoricamente. Desse pressuposto seguese o princípio da descontinuidade. Essa geração contribuiu para a concepção da história herdada de Koyré e Bachelard, ampliando e aprofundando seus princípios, procedimentos, metodologias e aplicações, e também inovando epistemologicamente com os conceitos de incomensurabilidade de Kuhn ${ }^{19}$ e de episteme de Foucault. ${ }^{20}$ Essas inovações conceituais têm profundas consequências para a metodologia e a epistemologia da história. Elas apontam para a impossibilidade de comunicação entre duas estruturas científicas, como também para uma rede de ligações entre novos signos e referências e, portanto, para uma nova racionalidade. Esses autores da terceira geração mencionam claramente sua oposição a uma concepção da história continuísta e teleológica que evolui em

\footnotetext{
${ }^{18}$ LÉVI-STRAUSS, Claude. O pensamento selvagem. Rio de Janeiro: Zahar, 1983.

${ }^{19}$ KUHN, Thomas. A estrutura das revoluções cientificas. São Paulo: Perspectiva, 1978.

${ }^{20}$ FOULCAUT, Michel. As palavras e as coisas. Lisboa: Portugalia, 1966.
} 
direção a uma verdade ou a um centro de referência. Eles demandam uma nova noção de progresso e uma nova noção de racionalidade, talvez uma racionalidade não-criterial. Thomas Kuhn descreve a característica metodológica comum a todos eles, de Koyré e Bachelard passando depois para Canguilhem, Foucault e Althusser, que é a de aplicar o método estruturalista no estudo da história, o que os faz visceralmente anticontinuístas e antiteleológicos, questionando seriamente a noção de progresso e também a da relação entre senso comum e ciência. Segundo Kuhn, mencionando Koyré, na abordagem da história:

Em vez de procurar as contribuições permanentes de uma ciência mais antiga para nossa perspectiva privilegiada, eles procuram "apresentar a integridade histórica daquela ciência, a partir de sua própria época”. Por exemplo, perguntam não pela relação entre as concepções de Galileu e as da ciência moderna, mas antes pela relação entre as concepções de Galileu e aquelas partilhadas por seu grupo, i. e., seus professores, contemporâneos e sucessores imediatos nas ciências. ${ }^{21}$

Uma ressalva deveria ser apresentada aqui quanto à concepção da história de Bachelard que, apesar de seus conceitos de corte e ruptura epistemológica, propõe uma história recorrente que se faça sempre do ponto de vista da ciência atual mostrando qual foi a trajetória seguida por ela até chegar à contemporaneidade. Essa recorrência está associada a uma ideia de progresso por acúmulo de conhecimento, como quer Duhem, ainda que não envolva a ideia teleológica de aproximação da verdade, como quer também Duhem.

Nesse contexto do problema da interpretação da história, portanto, da filosofia da história, a concepção da filosofia da história de Duhem, como continuísta, teleológica, cumulativa e convergentista para a verdade, forma o sólido pano de fundo de toda essa reflexão posterior da filosofia da história da ciência. Reflexão que produziu, com os autores mencionados, um grande impacto epistemológico e metodológico contemporâneo no modo como concebemos a ciência e sua relação com as demais disciplinas, em particular com grande impacto e repercussões na própria filosofia da história em geral. Contudo, essa concepção da filosofia da história de Duhem não teve a adequada abordagem e, por essa razão, o adequado reconhecimento. Permanece ainda bastante desconhecida, em parte devido à complexidade do trabalho do autor, que envolve a combinação de vários saberes, entre eles a física, a filosofia e a historia, em

\footnotetext{
${ }^{21}$ KUHN, Thomas, op. cit., 1978.
} 
parte devido à controvertida personalidade intelectual e conservadora do autor. Todos os autores mencionados, com a adição de Popper, Lakatos e Laudan, devem, mesmo sem mencioná-lo adequadamente em suas obras, muito de suas concepções a Duhem. No caso desses dois últimos, em particular a concepção de história e seu uso para a avaliação de metodologias. ${ }^{22}$

Agassi interpretou a concepção de história de Duhem como inteiramente convencionalista. ${ }^{23}$ R. N. D. Martin salientou o uso, por parte de Duhem, do método histórico para justificar sua posição epistemológica. ${ }^{24} \mathrm{H}$. W. Paul ofereceu perspectivas acerca da filosofia da história de Duhem. ${ }^{25}$ Explorando as questões que levantam com muitos detalhes, estabeleceremos, nesse trabalho, a concepção duhemiana de história da ciência e sua natureza e função, para proporcionar uma avaliação crítica de teses epistemológicas e metodológicas que compõem sua concepção acerca do próprio conhecimento científico. Todavia, o principal propósito deste artigo consiste em desenvolver argumentos, pela análise da natureza e da função da história, que enfraquecem, refutam e rejeitam uma interpretação convencionalista proposta por Agassi acerca da concepção duhemiana de história da ciência.

Uma análise cuidadosa dos estudos históricos de Duhem permite-nos distinguir, a título de clarificação, quatro aspectos amplos de sua concepção de história da ciência: (i) a natureza da história; (ii) a função e o papel da história; (iii) o objeto da história; e, finalmente, (iv) os recursos metodológicos, i. e., os objetivos, teses, princípios, regras e instrumentos empregados por Duhem em sua pesquisa e teorização históricas. Neste artigo, como já mencionamos, vamos nos concentrar nos dois primeiros aspectos de sua concepção da história. O resultado conceitual dessa análise será denominado: concepção “intelectualista/empirista" da história da ciência. Os vários enunciados que compreendem a concepção duhemiana de história se encontram espalhados ao longo de numerosos estudos históricos e serão agrupados em uma reconstrução histórica

\footnotetext{
${ }^{22}$ LAKATOS, Imre. História da ciência e suas reconstruções racionais. Lisboa: Edições 70, 1998; LAUDAN, Laurens. Progress and its problems. Berkeley: University of California Press, 1977. ${ }^{23}$ AGASSI, Joseph. Towards a historiography of science. History and Theory Supplement, 2, 1967, p. 28-40.

${ }^{24}$ MARTIN, R. Niall D. Darwin and Duhem. History of Science, 20, 1982, p. 64-74.

${ }^{25}$ PAUL, Harry W. Pierre Duhem: Science and the historian's craft. Journal of the History of Ideas, 33, 1972, p. 497-513.
} 
articulada, em conformidade com os compromissos filosóficos mais gerais de sua teoria da ciência.

Para iniciar, notemos que um curto ensaio de Duhem, "Les sciences historiques" como parte do seu La science allemande ${ }^{26}$ é o único trabalho publicado que discute as características gerais e os fundamentos teóricos de sua concepção de história, contendo, em particular, a única reflexão filosófica de Duhem acerca da natureza própria da história. Seu principal aspecto consiste no desenvolvimento de uma concepção de história que se posiciona em nítida oposição, por um lado, à proposta empirista/indutivista da história e, por outro, à concepção dogmática. Essa última é representada por uma ênfase excessiva e não-crítica do uso do método dedutivo como método básico da história, tal como praticada pelos historiadores alemães (Hegel, por exemplo). Agassi corretamente salienta o espírito anti-indutivista da concepção duhemiana da história da ciência, ${ }^{27}$ Contudo, ele a interpreta de modo equivocado, ao caracterizá-la como convencionalista. Duhem delineia, desde o princípio, a natureza específica de sua concepção de história através de uma afirmação inequivocamente anti-indutivista:

No início de toda pesquisa histórica, bem como no de toda pesquisa experimental, é preciso uma ideia preconcebida; esta ideia tem sido sugerida com frequência ao historiador por uma pista feliz, pela descoberta de algum monumento. [...] Esta ideia preconcebida deve ser submetida ao controle dos documentos e, para tanto, é preciso pesquisá-los. ${ }^{28}$

Duhem atribui uma natureza hipotética e conjectural às pressuposições históricas que contrastam com a proposta indutivista/empirista. De acordo com esta última, as proposições históricas são fatos generalizados obtidos por indução. A reflexão duhemiana acerca da natureza da história acompanha sua crítica devastadora (embora não se identifique com a mesma) dessa proposta. Não se pode transferir literalmente as consequências de sua análise crítica da física teórica para sua concepção acerca da natureza da história. Duhem destrói, ao longo de seus diversos ensaios sobre a natureza da física teórica, o fundamento conceitual sobre o qual se assentava o indutivismo/empirismo: a natureza do crescimento científico, da avaliação crítica de teorias rivais e, em particular, sua concepção do confronto entre teoria e experiência. No seu entender, uma avaliação sensata

\footnotetext{
${ }^{26}$ DUHEM, Pierre, op. cit., 1915, p. 51-72.

${ }^{27}$ AGASSI, Joseph, op. cit., 1967, p. 31-40.

${ }^{28}$ DUHEM, Pierre, op. cit., 1915, p. 53.
} 
da física matemática (com seu alto grau de desenvolvimento) indica a inviabilidade do físico (enquanto físico) para utilizar inferências puramente indutivas, ${ }^{29}$ bem como sua inadequação, em metaciência, para proporcionar uma descrição bem-sucedida da racionalidade do desenvolvimento científico.

Em oposição à proposta da metodologia empirista/indutivista, Duhem desenvolve uma concepção metodológica da ciência baseada em suas teses epistemológicas, cujo núcleo é formado pela tese que afirma a impregnação dos dados pela teoria (TEIDT), pela tese segundo a qual o método experimental não pode decidir nem pela verdade nem pela falsidade de proposições científicas (tese Duhem-Quine) e pela tese segundo a qual a teoria como um todo é que enfrenta o teste empírico e não suas proposições separadamente, ou seja, a tese $\mathrm{D} .{ }^{30}$ Essas teses, juntamente com algumas outras não mencionadas aqui, ${ }^{31}$ formam a base filosófica para rejeitar os dois elementos básicos da proposta metodológica empirista, a saber, (i) o princípio empirista da separabilidade e testabilidade isolada de hipóteses, e (ii) o método indutivista de construção da teoria física. Duhem substitui esse método pelo hipotético-dedutivo, e o princípio da separabilidade pela tese D (um princípio, no seu entender, mais adequado para interpretar a relação entre teoria e experiência) que, de modo mais preciso, afirma que não se pode separar e testar isoladamente as proposições científicas.

Além disso, ele retira dessas teses, das definições da teoria física como representação - considerada como um sistema formal para organizar e classificar as leis empíricas - e da definição complementar de teoria física como um sistema racional $^{32}$ a afirmação de que a relação entre teoria e experiência é caracterizada por uma indeterminação, ${ }^{33}$ possuindo, portanto, uma arbitrariedade intrínseca. A indeterminação epistemológica entre teoria e experiência caracteriza o estatuto metodológico e não lógico dessa relação. ${ }^{34} \mathrm{O}$ método de escolha para avaliar a escolha entre teorias físicas rivais emprega uma metodologia muito mais complexa do que aquela sugerida pelo método de escolha do empirismo/indutivismo. A te-

\footnotetext{
${ }^{29}$ DUHEM, Pierre. The aim and structure of physical theory. Atheneum Press, 1974, p. 193; DUHEM, Pierre. Traite d'énergétique ou thermodynamique générale. Paris: Gauthier-Villars, 1911, p. 330. ${ }^{30}$ DUHEM, Pierre. Notice sur les titres et travaux scientifiques de Pierre Duhem. Paris: GauthierVillars, 1917, p. 152; DUHEM, Pierre, op. cit., 1974, p. 190-199.

${ }^{31}$ CHIAPPIN, José Raymundo Novaes, op. cit., 1989, capítulo 3.

${ }^{32}$ Ibidem.

${ }^{33}$ DUHEM, Pierre, op. cit., 1974, p. 136-137.

${ }^{34}$ DUHEM, Pierre. Quelques réflexions au sujet des théories physiques. Revue des Questions Scientifiques, 31, 1892, p. 167.
} 
oria duhemiana da escolha foi longamente discutida em outro lugar ${ }^{35}$ juntamente $^{-}$ com o novo conceito epistemológico de física teórica que deve, no entender de Duhem, substituir tanto a visão convencionalista/pragmatista (que incorporou muito da metodologia indutivista/ empirista) quanto a proposta metafísica.

Dois pontos importantes devem ser salientados no tocante à concepção de Duhem sobre a natureza da teorização científica, ambos relacionados à sua reflexão sobre a história. Em primeiro lugar, Duhem defende a impregnação teórica do conhecimento empírico (TEIDT). Esse aspecto e sua consequência imediata para a relação entre teorias e experimentos, a tese D, são características intrínsecas dos sistemas racionais e axiomáticos. Essas duas teses epistemológicas, com efeito, se conectam com a ideia de que as teorias físicas são sistemas racionais. Assim, a física teórica é um sistema cujas relações entre suas hipóteses, conceitos e leis empíricas se estabelecem através de procedimentos de tipo more geometrico, envolvendo métodos matemáticos extremamente desenvolvidos, tais como o método lagrangiano. ${ }^{36}$ Surge a questão de saber se as teses epistemológicas mencionadas acima (que implicam uma concepção anti-indutivista da física teórica) são aplicáveis à história. Em segundo lugar, a distinção metodológica entre ciência propriamente dita e reflexão sobre a ciência (teoria da ciência) origina problemas de escolha e de legitimidade de metodologias (concepções epistemológicas da teoria física). Tal distinção coloca o problema de se a legitimidade das metodologias não se encontra na própria ordem científica. Identificar a natureza das teorias físicas é um problema, para Duhem, de ordem metodológica. Ele não o considera um problema científico, tal como o concebia a visão empirista/indutivista, que considerava o método experimental e a crítica lógica os únicos meios legítimos para examinar criticamente a ciência, nem tampouco um problema metafísico, tal como imaginavam os racionalistas clássicos de Descartes a Kant.

No que diz respeito ao primeiro ponto, a história, no entender de Duhem, é uma ciência empírica. Ele afirma que "a verdade histórica é uma verdade da experiência". ${ }^{37}$ Mas todas as ciências empíricas são hipotéticas, e a história mesma o é, embora não constitua um sistema dedutivo de proposições. A relação entre hipóteses, conceitos e fatos históricos não pode ser, assim, estabelecida

\footnotetext{
${ }^{35}$ CHIAPPIN, José Raymundo Novaes, op. cit., 1989, capítulo 3.

${ }^{36}$ DUHEM, Pierre, op. cit., 1915, p. 26-48.

${ }^{37}$ Ibidem, p. 53.
} 
por raciocínios do tipo more geometrico. Que a história seja uma ciência típica, embora não dedutiva, significa que as conexões entre pressupostos, fatos e informações tecidas na história caracterizam-se pelo "esprit de finesse", e não pelo "esprit de géométrie". ${ }^{38}$ Duhem afirma: Este trabalho histórico, é ao "esprit de finesse" que compete essencialmente realizar. ${ }^{39}$

Isso significa que as conexões entre as proposições históricas são de outra ordem que não a dedutiva. Analógicas, metafóricas e associativas, mas certamente não dedutivas. Consequentemente, não se justifica a transposição de sua metodologia anti-indutivista, dirigida à física teórica, para a história, uma ciência empírica que possui um estatuto epistemológico diferente da primeira. A ciência empírica adota uma metodologia distinta para construir a física e para avaliar seu confronto com a experiência. Não se pode afirmar, ao menos neste estágio de desenvolvimento da ciência empírica, que as proposições históricas são interpretadas no mesmo grau que as da física teórica. Duhem parece defender uma tendência natural do espírito humano em direção à organização teórica crescente. ${ }^{40}$ Essa tendência leva os conceitos, pressupostos e métodos da física de seu estágio puramente empírico a estágios de abstração e teorização crescentes. Leva a física da ciência empírica à física teórica, considerada como física matemática ${ }^{41}$ Esse processo é marcado pelo uso cada vez mais amplo de procedimentos dedutivos até que estes atinjam sua plena realização no raciocínio matemático. Duhem afirma:

Sucessivamente, ao longo das eras, tem-se visto os diversos capítulos da ciência física adquirir forma matemática. Desde os tempos de Platão e Aristóteles, Eudoxo e Calippe se esforçaram para construir uma teoria geométrica [...]. Com Arquimedes, a estática dos

\footnotetext{
${ }^{38}$ Duhem afirma claramente a diferença entre o "esprit de géométrie" e o "esprit de finesse". Segundo ele, pelo primeiro, "veem-se [afirma Pascal] os princípios [...]; e seria necessário ter uma mente desonesta para raciocinar equivocadamente sobre princípios tão óbvios, que é quase impossível que nos escapem". Por outro lado, o "esprit de finesse" é tal que "seus princípios se encontram no uso comum, diante dos olhos de todos. Não é necessário revirar-se, nem fazer violência. Trata-se apenas de ter boa visão, mas é preciso que esta seja boa; pois os princípios são tão vagos e numerosos que é quase impossível que ao menos um não nos escape. E a omissão de um princípio é uma fonte de erro [...]" (Ibidem, p. 30).

${ }^{39}$ Ibidem, p. 56.

${ }^{40}$ Ibidem, p. 32-33.

${ }^{41}$ Para Duhem, um dos exemplos de abstração e teorização crescentes, relativamente aos métodos de construção da física, consiste no desenvolvimento da mecânica de Newton (mecânica vetorial) à mecânica de Lagrange (mecânica analítica).
} 
sólidos pesados e a hidrostática assumiram, por sua vez, esta forma. A Idade Média [...] buscou preparar [...] a dinâmica matemática que Galileu e Descartes inaugurariam. ${ }^{42}$

Pode-se afirmar, a partir dessas considerações, que Duhem, como um teórico da ciência na mudança do século XIX para o século XX, parece defender uma evolução histórica e uma naturalização da epistemologia. Essa concepção evolutiva da história provém da percepção da evolução teórica da física e da transformação epistemológica de uma metodologia empirista - ajustada, então, para examinar a física como uma ciência puramente empírica - em uma metodologia empirista/intelectualista que se revela mais adequada para o estágio de desenvolvimento da física teórica em ascendente processo de maior abstração, generalidade e matematização, cuja tendência axiomática torna-se típica do final do século XIX e do início do século XX, como se nota nos trabalhos de fundamentação da teoria eletromagnética, nos trabalhos de termodinâmica de Gibbs (inclusive seus trabalhos de mecânica estatística), nos trabalhos matemáticos de Hadamard e também nos trabalhos matemático-físicos de Poincaré. O que resulta é uma epistemologia e uma metodologia mais adequadas para expressar a natureza do conhecimento científico, reconhecendo que a avaliação crítica deste último depende do seu estágio de desenvolvimento histórico. Todavia, apesar da tese duhemiana acerca da evolução do caráter epistemológico e metodológico da ciência empírica, é difícil saber se todas as ciências empíricas, e em particular a história, são governadas por essa tese. Provavelmente não. Duhem critica duramente a aplicação do método dedutivo à história, dirigindo suas críticas principalmente à escola alemã, sobretudo a Hegel ${ }^{43}$ que defende uma visão da história como uma ciência dedutiva. Ele apresenta dois argumentos contrários a essa proposta:

(i) A história não pode ser uma ciência dedutiva, pois seu assunto é o homem, e este é muito complexo para ser definido. Ele afirma:

[...] e a história não será jamais uma ciência dedutiva, porque o homem, do qual ela trata, é muito complexo, inacessível a qualquer definição, pois se move em meio a eventos por demais numerosos, sutis e intrincados. ${ }^{44}$

\footnotetext{
${ }^{42}$ Ibidem, p. 33.

${ }^{43}$ Ibidem, p. 22.

${ }^{44}$ Ibidem, p. 58.
} 
(ii) O domínio histórico não é governado pelo determinismo rigoroso, ele é o domínio do livre-arbítrio humano. Duhem observa que:

[...] jamais se pode afirmar que tais causas, que são conhecidas, produziram forçosamente tal resultado; sempre, com efeito, entre estas causas e isto que delas resultou, a vontade do homem se encontra envolvida, e esta vontade é livre. ${ }^{45}$

A principal ilustração da proposta anti-indutivista de Duhem acerca da ciência empírica reside no fato de que, nesse domínio, todas as investigações se iniciam com conjecturas e ideias preconcebidas, ao invés de fatos generalizados. ${ }^{46}$ Nas ciências empíricas, bem como nas teóricas, inicia-se com uma proposta, uma conjectura, e uma ideia preconcebida. As proposições históricas gerais não são fatos generalizados, mas hipóteses. Ora, se, por um lado, as teses epistemológicas, que definem sua concepção de ciência, implicam uma concepção anti-indutivista da teoria física, esta última concepção, por outro, não implica a tese da impregnação dos dados pela teoria nem tampouco a tese D. Desse modo, tanto o anti-indutivismo das ciências empíricas que não emprega raciocínios baseados em padrões geométricos e métodos matemáticos, quanto aquele que adota métodos empírico-matemáticos (física matemática) contêm algo de mais básico que os caracteriza: o caráter hipotético de suas pressuposições. Duhem indica explicitamente esse aspecto de sua concepção anti-indutivista de ciência. Ele afirma que, apesar de sua aceitação da tese acerca da origem observacional dos princípios físicos,

[...] estas experiências que explicam a gênese histórica dos princípios que ela [a física] formula, ela não as considera como capazes de conferir certeza alguma a tais princípios. Estes, ela os toma como puros postulados, como decretos arbitrários da razão. [...] O acordo com os ensinamentos da observação não está, pois, como o exigiria o método newtoniano, na origem da teoria física, seu lugar está no final. ${ }^{47}$

Assim, Duhem critica a visão incorreta do indutivismo newtoniano, mesmo sem apelar à tese D e à TEIDT, mas apenas com base no caráter hipotético da ciência empírica. Uma consequência importante da diferença entre sua crítica básica do indutivismo e aquela governada por essas duas teses consiste em que

\footnotetext{
${ }^{45}$ Ibidem, p. 59.

${ }^{46}$ Ibidem, p. 25-45.

${ }^{47}$ DUHEM, Pierre, op. cit., 1917, p. 152.
} 
a primeira (baseada no caráter hipotético da ciência) não rejeita a aplicação do princípio empirista da separabilidade e testabilidade de hipóteses isoladas. $\mathrm{O}$ teste de hipóteses, em certas ciências empíricas, tal como a fisiologia, opera com base no princípio da separabilidade. Esse aspecto metodológico da ciência empírica é importante para se conceber a história como um meio para legitimar os princípios metafísicos e as regras metodológicas de Duhem. ${ }^{48} \mathrm{~A}$ aplicação do princípio da separabilidade é tornada impraticável em física teórica pela transformação da ciência hipotético-empírica em ciência hipotético-dedutiva. $\mathrm{Na}$ física teórica, que envolve métodos matemáticos extremamente desenvolvidos, o uso de um sistema racional/axiomático de conceitos e hipóteses (expressos em linguagem matemática sofisticada) requer a construção de modelos idealizados que tornam muito complexa a relação com a experiência. ${ }^{49}$ Portanto, a natureza da física teórica, uma ciência empírico-matemática, é guiada pela tese epistemológica sobre a impregnação dos dados pela teoria (TEIDT) e pela tese epistemológica D da não separabilidade e testabilidade isolada das proposições científicas, assim como pela ideia da ciência como um sistema racional. O princípio da separabilidade e testabilidade isolada das proposições científicas não pode ser aplicado a uma ciência com essas características.

$\mathrm{Na}$ história como ciência hipotética, embora não dedutiva, uma vez que uma conjectura é apresentada, ela deve ser submetida ao teste pelos fatos. Esse processo de formular conjecturas e testá-las através da comparação de suas consequências com os fatos deve ser contínuo. Toda nova conjectura é apresentada no contexto de uma posição previamente atingida, e presumivelmente deve dar conta de mais fatos e eventos que aqueles já conhecidos. Duhem descreve o processo de aquisição de conhecimento na história da seguinte maneira:

Uma vez que nossa primeira suposição tenha sido rejeitada, é necessário formular outra que dê conta de todos os textos, de todos os momentos já conhecidos; a seguir, esta segunda suposição, é preciso, se possível, submetê-la ao controle de novos documentos; assim, através desta contínua comparação de nosso pensamento com os fatos, por esta incessante impressão dos fatos sobre nosso pensamento, uma verdade histórica pouco a pouco emergirá, mais precisa, colocada à plena luz. ${ }^{50}$

\footnotetext{
${ }^{48}$ Deve-se lembrar que Duhem rejeita a metafísica como um sistema fundacionalista da física. No seu entender, ela é antes uma coleção de princípios que guiam nossa razão. Seu propósito consiste, exatamente, em iluminar as relações entre tais princípios.

${ }^{49}$ DUHEM, Pierre, op. cit., 1911, capítulos 2, 3 e 4.

${ }^{50}$ DUHEM, Pierre, op. cit., 1915, p. 56.
} 
Parafraseando sua passagem acima, o processo de teste na história funciona da seguinte maneira: formulam-se hipóteses e, a seguir, suas consequências são comparadas com os fatos. A oposição com os fatos leva à rejeição da hipótese e sua substituição por uma conjectura aprimorada, e assim por diante. O princípio da separabilidade é pressuposto como metodologicamente adequado nesse processo de teste de pressupostos históricos. No entender de Duhem, os resultados de submeter conjecturas a diversos testes conduz àquilo que ele denomina uma "verdade histórica", da mesma forma que conjecturas empíricas podem se tornar leis empíricas em ciência. Duhem busca mostrar, juntamente com sua discussão teórica da natureza do processo histórico, que o processo de teste de hipóteses históricas não difere muito dos procedimentos que usamos na ciência empírica. Assim, o processo pelo qual se produzem verdades históricas é muito similar àquele por meio do qual são produzidas verdades empíricas. Duhem reconhece a similaridade entre a justificação de hipóteses em ciência e na história quando afirma:

Para justificar uma hipótese acerca das origens da monarquia carolíngia, um historiador não age de outro modo senão aquele que Pasteur adotaria para verificar uma hipótese sobre a causa da raiva. ${ }^{51}$

As verdades históricas não são fatos generalizados, mas pressuposições hipotéticas a serem testadas pelos fatos (documentos, manuscritos etc.). Duhem apresenta vários exemplos do que denomina "verdade histórica", a saber: (i) sua famosa tese $\mathrm{D} ;{ }^{52}$ (ii) seu princípio lógico de Carnot modificado que denominamos "princípio lógico-histórico de Carnot", o qual afirma que uma teoria contradita pelos dados (i. e., refutada) deve ser rejeitada se houver uma melhor, e mais ampla, disponível para substituí-la $a^{53}$ - essa regra metodológica, que compõe seu método crítico para avaliar teorias rivais, é sustentada por evidências históricas; (iii) o ideal epistemológico de uma teoria física completamente unificada e lógica (PUL) e da sua tese ontológica associada da existência de uma teoria física ideal (TOTFI) $;{ }^{54}$ (iv) a ideia de uma teoria da convergência da verdade expressa pela tese epistemológica (TCV) que afirma ser o progresso científico

\footnotetext{
${ }^{51}$ Ibidem, p. 56.

${ }^{52}$ DUHEM, Pierre. Les théories de l'optique. Revue des Deux Mondes, CXXIII, 1894, p. 122.

${ }^{53}$ DUHEM, Pierre. Les théories de la chaleur-II. Les créateurs de la thermodynamique. Revue des Deux Mondes, CXXX, 1895, p. 392.

${ }^{54}$ DUHEM, Pierre, op. cit., 1974, p. 296.
} 
uma aproximação gradual das teorias físicas à teoria física ideal descrita por TOTFI (descrevendo a estrutura do mundo).

Com relação ao segundo ponto, Duhem deve enfrentar, por assumir uma distinção metodológica entre ciência e reflexão sobre a ciência, o problema do estatuto epistêmico (normativo, naturalista, científico ou metafísico) de sua reflexão sobre a ciência, i. e., o problema da objetividade e legitimidade de sua metodologia. Esse problema, por sua vez, envolve uma concepção acerca da natureza da racionalidade. Como ele argumenta a favor de sua concepção? Como seu anti-indutivismo pode ser sustentado em detrimento do indutivismo newtoniano?

\section{Uma função da história: justificação dos princípios epistemológicos e metodológicos}

Na reconstrução da metodologia da teoria da ciência de Duhem percebese que seu objetivo é o de desenvolver uma concepção de teoria física como uma alternativa intermediária (middle ground) entre a concepção metafísica (dogmatismo) e a convencionalista/pragmatista (ceticismo). A construção dessa concepção não é científica, mas metodológica. A lógica da ciência decompõe-se em metodologia e metametodologia. Na metodologia desenvolvem-se as regras, as definições e os métodos de operacionalização da própria ciência, enquanto, na metametodologia, procura-se desenvolver suas estratégias para enfrentar o problema da legitimidade e da escolha de metodologias. Nela se dá a defesa do valor epistemológico de sua concepção relativamente às demais concepções de ciência, neste caso, à concepção indutivista da ciência. Mostrou-se que, no entender de Duhem, a racionalidade da aceitação de metodologias contém estas características: (i) a adequação dos meios aos fins, e (ii) a consistência holista dos princípios metodológicos e metacientíficos.

Essa concepção de racionalidade define o estatuto da teoria da ciência de Duhem (que proporciona a legitimidade de sua concepção de teoria física) como uma empresa inteiramente normativa. Contudo, tão importante quanto esse aspecto de seu conceito de racionalidade é o fato de que ele não exaure sua visão acerca da legitimidade das concepções epistemológicas (metodologias). Duhem não adota a posição de que a filosofia da ciência é uma empresa inteiramente normativa. Ao contrário, muitos de seus argumentos para legitimar seus princípios metacientíficos encontram-se baseados na análise histórica do desenvolvimento da ciência. Duhem adota explicitamente a tese de que os princípios metacientíficos devem também ser justificados pela evidência histó- 
rica. ${ }^{55}$ Segue-se, daqui, a tese segundo a qual Duhem defende uma concepção muito mais naturalista antes do que normativa da metodologia da ciência. O entendimento de Duhem de que a natureza da história é aquela de uma ciência empírica, ainda que não dedutiva, conecta-se com a ideia, no século XIX, da história vir a substituir a metafísica na função de proporcionar justificação e legitimidade aos fundamentos metodológicos do conhecimento. A história deve servir, com sua natureza de ciência empírica, de laboratório para testar os fundamentos metodológicos do conhecimento. Com essa estratégia epistemológica, Duhem recorre à história para proporcionar legitimação científica aos pressupostos anteriormente denominados de metafísicos da ciência. Ele defende assim uma naturalização da epistemologia e da metodologia em que a discussão sobre a natureza e a função da história é central. O presente artigo procura indicar, justamente, esse seu compromisso com uma visão naturalista, via história, da metodologia como um substituto para a fundamentação metafísica abalada, no século XVIII, tanto pelo próprio desenvolvimento científico quanto pela crítica epistemológica de Hume. Essa visão mais naturalista da concepção metodológica da ciência é uma de suas principais diferenças com a concepção de Popper que rejeita o recurso à história como método de análise, uma vez que sua concepção da ciência não tem a história como ciência. Mas esta análise acerca da concepção de Popper será deixada para um trabalho posterior.

A história da ciência exerce, quando desenvolvida como uma ciência hipotético-empírica, o papel de proporcionar evidências empíricas para teses metodológicas e epistemológicas. Caracterizando a história como uma ciência empírica, Duhem atribui à história a legitimidade necessária para ser utilizada no nível da justificação. As proposições históricas são de natureza conjectural e sujeitas isoladamente a teste, como na ciência empírica. Desse modo, a sua visão acerca da natureza da história como uma ciência empírica já contém sua função como um meio de justificar princípios metacientíficos. Além dessa função, a história também nos instrui (como uma fonte) acerca das categorias próprias, conceitos teóricos, valores e princípios normativos para construir uma teoria da ciência; todos eles tornam nossa concepção da teorização científica um empreendimento racional. $\mathrm{O}$ autor parece buscar, portanto, substituir parcialmente a concepção dogmática de Descartes e Kant pela visão naturalista da avaliação crítica da ciência. A história substitui o papel desempenhado pela metafísica no

$\overline{{ }^{55} \text { DUHEM, Pierre, op. cit., 1915, p. } 158 .}$ 
racionalismo clássico. No que diz respeito a este ponto, Duhem parece inclinarse para uma visão positivista segundo a qual os únicos procedimentos legítimos na teoria da ciência são a crítica lógica e o método empírico. Mas ele não se enredaria, nesse ponto, em um círculo vicioso? Parece-nos que não, pois ele busca legitimar metodologias (para construir teorias físicas) tomando a história como uma ciência empírica, e não teórica. Todavia, poder-se-ia ter uma regressão aqui, já que o problema da legitimidade dos métodos de construção da história é colocado (i. e., os métodos para construir suas generalizações). Além disso, seu trabalho revela que essa função de proporcionar a testabilidade de metodologias não é a única que se espera da história da ciência. Há muitas outras ainda.

É certo que sua função mais proeminente e significativa consiste (i) em instruir-nos acerca do caráter de nossa reflexão sobre a ciência, acerca das categorias, conceitos teóricos, valores e princípios normativos para construir uma teoria da ciência. Compete à história, também, apresentar justificação adicional e legitimidade para os componentes epistemológicos e metodológicos desta última. Além disso, no entanto, Duhem pretende que ela (ii) proporcione legitimidade à sua proposta específica de substituição da mecânica pela termodinâmica, como o novo código da física, ${ }^{56}$ e (iii) justifique ainda proposições científicas, servindo como um método heurístico ${ }^{57}$ Duhem aplica sua concepção acerca da natureza da história $a^{58}$ ao utilizar a própria história para realizar essas funções. Encontra-se estabelecido que sua concepção da racionalidade não se reduz, para lidar com o problema da legitimidade das metodologias científicas, à sua faceta normativa. $\mathrm{O}$ autor também examina esse problema de um ponto de vista naturalista, que passaremos a considerar agora.

Pode-se afirmar que Duhem segue a tradição do filósofo francês A. Comte, tal como Lakatos e Laudan muito mais tarde, ao conceber a história como um meio de justificar concepções epistemológicas sobre a ciência. Denominamos seu compromisso de fazer esse uso da história sua primeira tese historiográfica: TH-1. Com efeito, ele afirma explicitamente:

Todo pensamento abstrato tem necessidade do controle dos fatos; toda teoria científica apela à comparação com a experiência; nossas considerações de lógica sobre o método

\footnotetext{
${ }^{56}$ DUHEM, Pierre, op. cit., 1911, Introdução.

${ }^{57}$ Ibidem, Introdução.

${ }^{58}$ As proposições históricas não devem ser consideradas como fatos generalizados, mas como meras conjecturas, propostas a serem submetidas isoladamente ao teste pelos documentos etc.
} 
próprio à física não podem ser adequadamente julgadas se não forem confrontadas com os ensinamentos da história. ${ }^{59}$

Assim, de modo inequívoco, trata-se de uma função da história proporcionar os meios de testar empiricamente as afirmações epistemológicas e metodológicas de uma teoria da ciência. Caracterizamos esse compromisso como uma abordagem naturalista do problema da legitimidade e objetividade das metodologias científicas. Um entendimento mais completo dessa função da história de justificação de metodologias e epistemologias pode ser bem conduzido apenas se compreendermos também que a concepção da história de Duhem decompõe-se em duas outras concepções: uma formal e outra intelectual. Elas têm naturezas diferentes. Neste artigo, a discussão concentra-se mais propriamente sobre a concepção geral da história, em particular sobre sua natureza e função. Uma abordagem sobre a história intelectual, seu objeto, seus princípios e teses historiográficas é tema de outro artigo, assim como também a outra versão, que é a da história formal. Pode-se adiantar que a história intelectual é uma versão operacionalizada, em termos metodológicos, dessa concepção mais geral, não se colocando como distinta em natureza nem em função. A diferença mais profunda é com a história formal que demanda uma metodologia apropriada e que se confunde com o método abstrato; ela tem ainda o objetivo de fazer valer o princípio da continuidade das teorias científicas, mostrando-os em um progresso cumulativo de teorias numa sucessão em direção à teoria ideal.

\section{A fundamentação histórica da concepção da ciência como meio termo entre metafísica/dogmatismo e relativismo/ceticismo}

A discussão precedente defende a ideia da importância do emprego da história para legitimar os componentes metodológicos e epistemológicos das concepções de ciência em substituição ao método da fundamentação metafísica que tinha vigorado por toda a Idade Clássica. Duhem reivindica essa concepção da história, bem ao estilo de como Habermas mais tarde interpretou seu uso, tanto por Mach quanto por Comte, substituindo a fundamentação da ciência a partir da metafísica. Duhem faz uso da história também para tornar legítima sua concepção de física teórica que é, essencialmente, como visto, um termo médio (middle way) entre as concepções metafísica e pragmatista/convencionalista. Ao

\footnotetext{
${ }^{59}$ DUHEM, Pierre, op. cit., 1917, p. 158 (grifos nossos).
} 
longo de seus estudos históricos, percebe-se que a história surge naturalmente, tanto como um substituto para a abordagem metafísica do racionalismo clássico (Descartes e Kant) quanto para evitar o ceticismo que tal ausência poderia gerar. Duhem argumenta, com esses recursos da história, a favor de suas propostas epistemológicas, axiológicas e metodológicas sobre a ciência, porém mais particularmente em defesa de sua concepção de ciência como um meio-termo entre a metafísica (dogmática) e o pragmatismo/convencionalismo (ceticismo).

Duhem reconhece as limitações da lógica e do método empírico para a análise das teorias físicas, necessitando, assim, de maneira essencial, de proposições metacientíficas (metafísicas) para avaliar a racionalidade do crescimento científico. Ele afirma:

O estudo dos procedimentos através dos quais a ciência física progride [método experimental] não lhe revela a inteira justificativa dessa evolução. As tendências que dirigem o desenvolvimento da teoria física não são, portanto, completamente inteligíveis ao físico se ele deseja ser exclusivamente um físico. ${ }^{60}$

A sua concepção acerca da inteligibilidade da evolução das teorias físicas encontra-se dispersa ao longo de sua obra. Reconstruímos aqui o que pensamos tratar-se dos princípios básicos de sua teoria da ciência. O reconhecimento desses princípios requer uma investigação acerca da natureza do conhecimento científico que transcende seu trabalho qua físico. A parte metafísica de sua teoria da ciência afirma duas teses axiológicas básicas, teses acerca da natureza do mundo e do conhecimento. A primeira delas menciona o compromisso com a demarcação entre metafísica e física teórica, bem como entre física teórica e experimental que denominamos de tese axiológica (TA-1). Essa tese é formulada de modo que Duhem se distancie de concepções metafísicas e empiristas/indutivistas. A segunda tese axiológica (TA-2) estabelece que a construção de uma concepção de teoria física deve ter por objetivo a racionalidade e a continuidade do progresso científico. Essa tese axiológica, para Duhem, tem a função de dar a diretriz para demarcar sua concepção da ciência da do pragmatismo/convencionalismo. A estrutura metafísica da teoria da ciência envolve um conjunto de teses epistemológicas e ontológicas as quais proporcionam uma justificativa para esses princípios axiológicos.

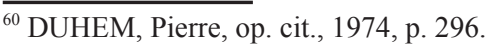


A lógica da ciência estipula um conjunto de regras metodológicas através das quais Duhem operacionaliza uma concepção acerca do objetivo da física teórica e de seu crescimento em conformidade com seus pronunciamentos metafísicos. É esse conjunto de regras metodológicas, em particular sua teoria da escolha, que concede substância às suas teorias da racionalidade científica e do progresso. Sua teoria da ciência define uma teoria do progresso através da teoria da convergência da verdade que proporciona os recursos para atribuir racionalidade à história da física. Sua concepção da racionalidade científica expressa um meio-termo (middle ground) entre a concepção clássica (dogmática) e a concepção cética moderna (convencionalismo/pragmatismo). Sua ideia de racionalidade obtém sua inspiração filosófica na filosofia de Pascal, ao invés da de Kant ou de Bergson (Le Roy). Com efeito, seu conceito de racionalidade científica é guiado pelo seguinte enunciado de Pascal:

Temos uma impotência de provar invencível por qualquer dogmatismo, e uma ideia de verdade invencível a todo pirronismo. ${ }^{61}$

Duhem $^{62}$ indica explicitamente que a ideia de racionalidade que embasa sua concepção sobre a ciência não é nem aquela de um dedutivismo puramente lógico, que define uma certeza metafísica, ${ }^{63}$ nem aquela de uma postura exclusivamente empírica, que define uma certeza prática que contempla a compatibilidade de dados empíricos com infinitas teorias e, portanto, que acabaria por originar o ceticismo.

O dogmatismo do dedutivismo lógico pode ser evitado pela demarcação entre metafísica e física. Não há qualquer dedutivismo lógico entre esses dois domínios. O primeiro pode proporcionar regras para guiar nossa construção e análise crítica da ciência, mas esta última não é extraída da metafísica. ${ }^{64}$ Duhem rejeita a concepção fundacionalista da metafísica. Desse modo, a relação entre metafísica e física, na visão de Duhem, não é dedutiva. Antes disso, acreditamos tratar-se de relação entre meios e fins, uma relação de suficiência, não de necessidade. Isso significa que as teses axiológicas TA-1 e TA-2 não definem conclusivamente a metodologia para construir a teoria física que deve realizá-las, e que a legitimidade depende da aceitação desses objetivos (TA-1 e TA-2) que

\footnotetext{
${ }^{61}$ DUHEM, Pierre, op. cit., 1915, p. 17; DUHEM, Pierre, op. cit., 1974, p. 335.

${ }^{62}$ DUHEM, Pierre, op. cit., 1915, p. 18.

${ }^{63}$ Duhem afirma que Kant explicitou esse equívoco dos sistemas metafísicos clássicos de Descartes e de Spinoza.

${ }^{64}$ DUHEM, Pierre. Physique et métaphysique. Revue des Questions Scientifiques, 34, 1893, p. 58-61.
} 
Duhem espera de sua teoria da ciência. No seu entender, o recurso metodológico - sua lógica da ciência - é suficiente, embora não necessário, para construir uma concepção de teoria física que realize tais objetivos. Os meios podem ser subdeterminados com respeito aos fins. Desse modo, há, em princípio, muitas metodologias rivais que podem ser apresentadas para realizar os objetivos propostos. Contudo, o ceticismo típico da concepção pragmatista/empirista é evitado, assumindo-se princípios metafísicos acerca da natureza do mundo e do conhecimento científico, juntamente com padrões, objetivos e métodos críticos para avaliar e legitimar metodologias. Vale notar que, no entender de Duhem, o enunciado de Pascal é também uma conclusão teórica e filosófica da reflexão kantiana acerca da natureza do próprio conhecimento científico. Duhem afirma:

O que é a Crítica da razão pura? O comentário mais longo, mais obscuro, mais confuso, o mais pedante desta passagem de Pascal: "Temos uma impotência de provar invencível por qualquer dogmatismo". [...] Com certeza, o ceticismo absoluto não é a última palavra do filósofo de Koenisberg acerca da fórmula de Pascal, ele vai igualmente justificar o segundo membro e mostrar que temos "uma ideia de verdade invencível a todo pirronismo". É o objeto da Crítica da razão pura. ${ }^{65}$

A busca, por parte de Duhem, de uma concepção de física teórica como um termo médio (middle way) entre as propostas metafísica (dogmática) e pragmatista/ convencionalista (cética) provém dessa tradição crítica de análise do conhecimento. Ele não rejeita completamente a metafísica, mas a considera essencial para iluminar a relação entre os princípios que guiam nossa razão. No entanto, ele de fato rejeita a visão fundacionalista da metafísica (Kant e Descartes), i. e., recusa um fundamento metafísico último. Cumpre notar que semelhante recusa é mais prática que teórica. ${ }^{66}$ Duhem substitui o papel que a visão fundacionalista atribui à metafísica pela história. No seu entender, esta última proporciona legitimidade para nossos princípios transcendentes. Além disso, ela nos instrui acerca de nossas teses sobre a física teórica, e a própria história da ciência é utilizada para proporcionar evidência empírica a favor de sua concepção como um meiotermo (middle ground) entre dogmatismo e ceticismo. Para Duhem, a história da ciência mostra, de maneira inequívoca, uma tensão essencial entre visões realistas (dogmáticas) e convencionalistas/pragmatistas (céticas) da ciência. $\mathrm{O}$

\footnotetext{
${ }^{65}$ DUHEM, Pierre, op. cit., 1915, p. 17-18.

${ }^{66}$ DUHEM, Pierre, op. cit., 1893, p. 58-61.
} 
cenário histórico de tensão entre essas duas propostas constitui um dos aspectos que ele apresenta em seu Le système $d u$ monde, ${ }^{67}$ cujos principais elementos epistemológicos se encontram condensados em seu To save the phenomena. ${ }^{68}$

A história do desenvolvimento científico proporciona evidência favorável à sua tese da inadequação do modelo do racionalismo clássico. Este repousa sobre a visão dogmática de um sistema de enunciados a priori e imutáveis (princípios autoevidentes e ideias claras e distintas em Descartes, e um referencial imutável de princípios sintéticos a priori em Kant) acerca dos fundamentos do mundo e/ou dos fundamentos do conhecimento. A história também apresenta evidências das limitações e da insuficiência do modelo convencionalista/pragmatista, baseado na lógica e na experiência para atribuir racionalidade ao empreendimento científico. Duhem com frequência salienta esse papel evidencial único da história para encontrar o equilíbrio entre as duas concepções globais sobre a ciência. ${ }^{69}$ Afirma o papel terapêutico da história para o bom senso da terceira via do físico:

A história da ciência apenas pode conter o físico tanto da louca ambição do dogmatismo [abordagem metafísica clássica], como do desespero do ceticismo pirrônico [pragmatismo contemporâneo]. ${ }^{70}$

No seu entender, com efeito, a história da ciência revela à filosofia da ciência evidências empíricas do espetáculo de quão provisórias são as teorias físicas. Desse modo, ele mostra a dificuldade de legitimar, de maneira definitiva e absoluta (como Kant tentou com a física newtoniana e Descartes com a concepção mecanicista da natureza), qualquer hipótese ou teoria científica específica. Segundo ele:

[O físico] ao retomar a longa série de erros e hesitações que precedem a descoberta de cada princípio, coloca-se em posição de defesa contra falsas evidências; relembrando as vicissitudes das escolas cosmológicas e desenterrando doutrinas uma vez triunfantes

\footnotetext{
${ }^{67}$ DUHEM, Pierre. Le système du monde. Paris: Librairie Scientifique Hermann et C., 1954-1959. ${ }^{68}$ DUHEM, Pierre. To save the phenomena. Chicago: University of Chicago, 1985.

${ }^{69}$ A discussão acerca dos critérios extralógicos e extraempíricos para legitimar e decidir entre concepções alternativas da física teórica foi feita em outro lugar. CHIAPPIN, José Raymundo Novaes, op. cit., 1989, capítulo 3.

${ }^{70}$ DUHEM, Pierre, op. cit., 1974, p. 270.
} 
do esquecimento no qual se encontravam, faz com que se lembre que os sistemas mais atraentes são apenas representações provisórias e não explicações definitivas. ${ }^{71}$

Por exemplo, a história apresentada por Duhem sobre a evolução da mecânica e da termodinâmica descreve a ascensão e queda de diferentes visões sobre a explicação mecânica dos fenômenos, bem como as dificuldades enfrentadas pelo programa mecanicista no sentido de proporcionar uma concepção unificada da física.

Mas a história da ciência também mostra evidências empíricas da possibilidade de um crescimento científico contínuo e cumulativo, indicando uma unificação crescente das teorias físicas e, assim, uma acumulação de leis empíricas sucessivamente aprimoradas. Há uma tendência na busca de teorias físicas mais amplas, englobando novas leis empíricas. Além disso, para Duhem, a história da ciência sugere que a termodinâmica é o esquema físico mais adequado para realizar o objetivo de unificar toda a física contemporânea. ${ }^{72}$ Ela indica, ainda, que essa tendência do desenvolvimento da ciência não é apenas em direção a teorias mais amplas, mas a uma classificação natural que reflete a estrutura real do mundo expressa pelas teses ontológica (TO) e epistemológica da convergência da verdade (TCV). Assim, do ponto de vista de Duhem, a história da ciência nos instrui acerca de certas características do progresso científico que mostram a inadequação da proposta pragmatista/convencionalista para lidar com sua racionalidade. Por exemplo, o tom cético dessa proposta, com sua interpretação da física teórica como mero instrumento, não pode explicar essa tendência em direção a uma teoria física unificada, uma teoria que, segundo Duhem, constitui uma classificação natural. No seu entender, a história nos mostra que as teorias físicas nos proporcionam, além de um conhecimento prático, um conhecimento teórico. Ele afirma:

Desdobrando diante dele [do físico] a tradição contínua através da qual a ciência de cada época se nutre com os sistemas de séculos anteriores, e gera a física do futuro; mencionando-lhe as previsões que a teoria formulou e os experimentos realizados; através disso, ela [a história da ciência] cria e fortalece nele aquela conviç̧ão de que a teoria física não é apenas um sistema artificial, adequado hoje e inútil amanhã, mas

\footnotetext{
${ }^{71}$ Ibidem, p. 270.

${ }^{72}$ DUHEM, Pierre. Evolution of mechanics. The Netherlands: Sijthoff \& Noordhoff, 1980, Conclusão; DUHEM, Pierre, op. cit., 1911, Introdução; DUHEM, Pierre. L'évolution des théories physiques du XVII siècle jusqu'à nos jours. Revue des Questions Scientifiques, 40, 1896, p. 463-499, p. 497-499.
} 
sim uma classificação cada vez mais natural, um reflexo paulatinamente mais claro das realidades que o método experimental não pode contemplar diretamente. ${ }^{73}$

Essa passagem descreve, de modo explícito, a rejeição do ceticismo por parte de Duhem, trazendo-nos de volta à sua teoria da ciência. Pode-se compreender, agora, a natureza de suas teses transcendentes acerca da natureza do mundo e do conhecimento. Tais teses proporcionam as condições para se dar conta, racionalmente, tanto do progresso em direção à teoria física ideal, como da unidade entre conhecimento prático e teórico. Ao fazê-lo, estabelecem com clareza a oposição, por parte de Duhem, à proposta convencionalista/pragmatista tanto no caso da ciência quanto no da história.

\section{Conclusão}

A proposta de Duhem de uma filosofia da história tem como primeiro traço o de identificar a natureza da história como sendo aquela de uma ciência hipotético-empírica, mas não dedutiva, e daí sua crítica à concepção hegeliana da história. O segundo traço associado à sua filosofia da história é o de atribuir à história o princípio da continuidade, que será tratado em outro artigo, seguido pelo desenvolvimento de todo um aparato metodológico de como aplicá-lo à história. Essa concepção hipotético-empírica da história tem várias funções, sendo uma delas aquela de justificar os princípios epistemológicos que servem ao propósito de definir a concepção da ciência. A história tem a função de legitimação em substituição a esse propósito clássico da metafísica. Neste texto mostra-se que Duhem recorre à história para justificar sua concepção da ciência como um tertius entre o dogmatismo e o ceticismo. Segundo Duhem, uma concepção da história com essa natureza e função, aplicada ao estudo do desenvolvimento dos conceitos, teorias e ideias científicas, com a metodologia apropriada, revela a ideia de um progresso sistemático, contínuo e racional da ciência. Essa noção de progresso toma a forma, sob os escombros de movimentos alternantes de ascensão e queda de ideias e conceitos intelectuais, de uma sucessão de teorias formais encaixadas umas nas outras e convergindo para uma classificação natural como teoria ideal. ${ }^{74}$ Não há como contemplar esse progresso da ciência sem o recurso à história e a uma filosofia da história que a tenha como empírica e continuísta.

\footnotetext{
${ }_{73}$ DUHEM, Pierre, op. cit., 1974, p. 270 (grifos nossos).

${ }^{74}$ DUHEM, Pierre, op. cit., 1892, p. 139-177; DUHEM, Pierre, op. cit., 1893, p. 55-83; DUHEM,
} 


\section{Referências bibliográficas}

AGASSI, Joseph. Towards a historiography of science. History and Theory Supplement, 2, 1967.

AGASSI, Joseph. Continuity and discontinuity in the history of science. Journal of the History of Ideas, 34, 1973, p. 609-626.

ALTHUSSER, Louis. Ler O Capital. Rio de Janeiro: Zahar, 1979.

BACHELARD, Gaston. O novo espírito científico. São Paulo: Abril Cultural, 1978.

BACHELARD, Gaston. A filosofia do não. São Paulo: Abril Cultural, 1978.

BACHELARD, Gaston. El compromiso racionalista. México: Siglo XXI, 1972.

BACHELARD, Gaston. A formação do espírito científico. Rio de Janeiro: Contraponto, 1999.

CANGUILHEM, George. Étude d'histoire et de philosophie des sciences. Paris: Vrin, 1968.

CHIAPPIN, José Raymundo Novaes. Duhem's theory of science: an interplay between philosophy and history of science. Ph.D. thesis, University of Pittsburgh, Pittsburgh, 1989.

DUHEM, Pierre. Quelques réflexions au sujet des théories physiques. Revue des Questions Scientifiques, 31, 1892, p. 139-177.

DUHEM, Pierre. Physique et métaphysique. Revue des Questions Scientifiques, 34, 1893, p. 55-83.

DUHEM, Pierre. Les théories de l'optique. Revue des Deux Mondes, CXXIII, 1894, p. 94-125.

DUHEM, Pierre. Les théories de la chaleur-II. Les créateurs de la thermodynamique. Revue des Deux Mondes, CXXX, 1895, p. 380-415.

DUHEM, Pierre. L'évolution des théories physiques du XVII siècle jusqu'à nos jours. Revue des Questions Scientifiques, 40, 1896, p. 463-499.

DUHEM, Pierre. Traite d'énergétique ou thermodynamique générale. Paris: Gauthier-Villars, 1911.

DUHEM, Pierre. La science allemande. Paris: A. Hermann et fils, 1915.

DUHEM, Pierre. Notice sur les titres et travaux scientifiques de Pierre Duhem. Paris: Gauthier-Villars, 1917.

DUHEM, Pierre. Le système du monde. Paris: Librairie Scientifique Hermann et C., 1954-1959.

DUHEM, Pierre. The aim and structure of physical theory. Atheneum Press, 1974.

Pierre, op. cit., 1894, p. 94-125. 
DUHEM, Pierre. Evolution of mechanics. The Netherlands: Sijthoff \& Noordhoff, 1980.

DUHEM, Pierre. To save the phenomena. Chicago: University of Chicago, 1985.

FOUCAULT, Michel. As palavras e as coisas. Lisboa: Portugalia. 1966.

HABERMAS, Jurgen. Knowledge and human interests. Boston: Beacon Press, 1971.

KOYRÉ, Alexandre. Études galiléennes. Paris: Hermann, 1966.

KOYRÉ, Alexandre. La révolution astronomique. Paris: Hermann, 1974.

KUHN, Thomas S. A estrutura das revoluções cientificas. São Paulo: Perspectiva, 1978.

LÉVI-STRAUSS, Claude. O pensamento selvagem. Rio de Janeiro: Zahar, 1983.

LAKATOS, Imre. História da ciência e suas reconstruções racionais. Lisboa: Edições 70, 1998.

LAUDAN, Laurens. Progress and its problems. Berkeley: University of California Press, 1977.

MARTIN, R. Niall D. The Genesis of a mediaeval historian: Pierre Duhem and the origins of statics. Annals of Science, 33, 1936, p. 119-129.

MARTIN, R. Niall D. The philosophy of physics according to Pierre Duhem. Ph.D. thesis, London School of Economics, 1981.

MARTIN, R. Niall D. Darwin and Duhem. History of Science, 20, 1982, p. 64-74.

MEYERSON, Emile. Identity and reality. New York: The Macmillan Co., 1930.

PAUL, Harry W. Pierre Duhem: Science and the historian's craft. Journal of the History of Ideas, 33, 1972, p. 497-513.

Recebido: julho/2008 - Aprovado: junho/2009 